\title{
A CRIANÇA [POBRE] EM ESCOLA CATÓLICA NA CIDADE PAROQUIAL DE JARDIM DO SERIDÓ (RIO GRANDE DO NORTE, 1943-1951) ${ }^{1}$
}

Marta Maria de Araújo *

\section{RESUMO}

A escolarização primária da criança pobre nas décadas de 1940 e 1950, no Rio Grande do Norte, postula ao historiador da educação investigála a partir de constatações empíricas. Por um lado, a educação escolar e a assistência social e material estiveram conjugadas pela cooperação celebrada por órgãos federais, organismos internacionais, instituições estaduais e a Igreja Católica. Por outro lado, impelido pela grave situação social da criança sem escola, mal vestida, de pés-descalços e subalimentada, a vaguear ociosamente nas cidades paroquiais e em suas capelas, na então região do Seridó, Dom José de Medeiros Delgado (1941-1951), o primeiro bispo de Caicó (RN) implantou nesses lugares uma rede de 18 escolas católicas primárias genericamente denominadas Escolas do Pobre, orientadas pela Casa do Pobre, à época órgão de direção das atividades assistenciais da Igreja Católica local. A investigação nucleada em torno da problemática do alfabetismo tem o objetivo de refletir sobre a materialidade educativa instaurada na Escola [do pobre] Rural "Jardim Seridoense", da cidade paroquial de Jardim do Seridó (RN) no período de 1943 e 1951. Considerando estritamente as singularidades dessa instituição católica, ancoramo-nos em construtos teóricos de cultura escolar e de cultura de escola, desenvolvidos pelo historiador da educação João Barroso (2004), que partiu das inter-relações entre organização societária e instituição educacional. Coincidindo sua instalação com a fase correspondente à

${ }^{1}$ Trabalho resultante da investigação Escolas do Pobre que foram criadas por Dom José de Medeiros Delgado, primeiro bispo diocesano de Caicó, Rio Grande do Norte (1941-1951).

* Doutora em Educação pela Universidade de São Paulo e Professora de História da Educação da Universidade Federal do Rio Grande do Norte. Editora do periódico "Educação em Questão". E-mail: martaujo@digi.com.br. 
planificação nacional da escolarização primária, a Escola [do Pobre] Rural "Jardim Seridoense" ergue-se, à semelhança de suas congêneres, como instituição social por excelência com o ensejo de que as crianças de 7 a 12 anos se apossassem de conhecimentos culturais mínimos e de hábitos de trabalho para ofícios em demandas à época.

PALAVRAS-CHAVE: Rio Grande do Norte. Dom José de Medeiros Delgado. Escola Rural "Jardim Seridoense". Escolas católicas do pobre. Materialidade educativa.

\begin{abstract}
The poor child elementary scholarship in the 1940's and 1950's, in the Rio Grande do Norte State, requires the Education historiographer to investigate it from the empiric verifications. On the one hand, the scholar education and the social and material assistance conjugate by the federal agencies cooperation, international corporates, state institutions and the Catholic Church. By the other hand, impelled by the grave child social situation, lacking from school, dressed badly, barefoot and underfed, lazily rambling on the parochial cities and in its chapels, in the former Serido region, Dom José de Medeiros Delgado (1941-1951), the first Caicó's (RN) bishop, implanted in these places an 18 catholic elementary schools network generically denominate Schools for the Poor, oriented by the House of the Poor, in that time a direction organism of the local Catholic Church attendance activities. The investigation centered around the problematic teaching to read and write process has the purpose to reflect about the educative materialism initiated in the Countryside School (of the poor) "Jardim Seridoense", of the parochial city of Jardim do Seridó city (RN) on the period between 1943 and 1951. Strictly considering the singularities of this catholic institution, we ground ourselves on the scholar culture and culture of the school theoric constructions, developed by the Education historiographer João Barroso (2004), who start from the inter-relations between societary organization and educational institution. Having coincide its installation to the correspondent period of the national elementary scholarship delineate, the Countryside School (of the poor)
\end{abstract}


"Jardim Seridoense" raises, in the likeness of its congener, as a social institution par excellence with the desire that the 7 to 12 years old children take possession of the minimum cultural knowledge and the work habits for the workmanship required at that time.

KEYWORDS: Rio Grande do Norte. Dom José de Medeiros Delgado. Countryside School "Jardim Seridoense". Catholic Church schools for the poor. Educative materialism.

Nas décadas de 1940 e 1950, o acesso às letras, à instrução moral, à preparação para a vida e à proteção à saúde da infância brasileira, bem como a planificação nacional da escolarização primária ganharam centralidade, no Programa de Reconstrução Nacional do governo de Getúlio Dornelles Vargas (1930-1954). Nessa perspectiva, a educação escolar e a assistência social, material e espiritual estiveram conjugadas pela cooperação celebrada entre órgãos federais (Ministério da Educação e Saúde, Ministério da Agricultura, Departamento Nacional da Criança e Legião Brasileira de Assistência), instituições estaduais (Secretaria de Estado de Educação, Serviço Estadual de Reeducação e Assistência Social), organismos internacionais (Organização das Nações Unidas) e a Igreja Católica (Ação Católica, Caritas brasileira, congregações e ordens religiosas).

Já no início da década de 1940 (17 de fevereiro de 1940), o governo de Getúlio Vargas decretou a instalação do Departamento Nacional da Criança, para constituir-se como órgão do Ministério da Educação e da Saúde Pública, coordenador das atividades nacionais relativas à proteção, à infância, à adolescência e à maternidade. (Decreto-lei no 2.024 , de 17 de fevereiro de 1940).

Especialmente à criança na fase da escolarização garantir-se-ia amparo para um desenvolvimento mental, moral, físico e a preparação para a vida. Visando a concretização desse projeto, os poderes públicos estimularam a cooperação com instituições particulares. No ano de 1948, o Departamento Nacional da Criança foi reestruturado com a criação das delegacias federais da criança nas capitais brasileiras. Para o alcance dessa 
política social contava-se com um colaborador imprescindível - a Igreja Católica. No parecer de Sousa:

Um auxílio extra na recomposição dessa política social veio por conta do pacto estabelecido com a Igreja, cujo objetivo era a realização, no plano prático, de sua doutrina social, atendendo ao interesse primordial de reordenar o espaço social por meio da harmonia e da colaboração entre as classes sociais. (SOUSA, 2000, p. 249).

Impelido pela grave situação social da criança sem escola, mal vestida, pés-descalços e subalimentada, a vaguear ociosamente nas cidades paroquiais e capelas da então região do Seridó, o primeiro bispo de Caicó (RN), Dom José de Medeiros Delgado (1941-1951), implantou entre março e maio de 1943, uma rede de 18 escolas católicas primárias, genericamente denominadas Escolas do Pobre, orientadas pela Casa do Pobre, à época órgão de direção das atividades assistenciais da Igreja Católica local.

No ano 1940, o Rio Grande do Norte possuía uma população de 773.681 habitantes. Os que moravam na zona urbana eram 166.138 e os do meio rural chegavam a 607.543. Nesse mesmo período, a população do município de Caicó correspondia a 25.233 habitantes, dos quais 4.636 viviam na zona urbana e 20.596 moravam no meio rural. O número de analfabetos totalizava 12.895 , sendo 6.242 homens e 6.652 mulheres. (Instituto Brasileiro de Geografia e Estatística, 1952).

Tratando com desvelo as crianças pobres da então região Seridó do Rio Grande do Norte, Dom Delgado preconizava que lhes oferecendo educação escolar daria asas à inteligência e ao coração infantil. As Escolas dos Pobres e as demais criadas por Dom Delgado receberam dele o epíteto "escola de inteligência e de amor". (DELGADO, [1944], p. 4, grifo nossos). Decidindo-se Dom José de Medeiros Delgado pela implantação de uma rede de Escolas do Pobre (1943 a 1951) em nível primário nomeou para dirigi-las os párocos, curas d'almas, com a colaboração ou não de irmandades ou confrarias católicas.

A fundação da Casa do Pobre (decreto canônico de 15 de março de 1943), com sede na cidade episcopal de Caicó e filiais nas sedes paroquiais e nas suas capelas, representava "[...] a instituição diocesana 
como órgão de atividade social dos católicos entre nós, destinando-se a todo e qualquer serviço de assistência nesta Diocese." (Estatutos da Casa do Pobre da Diocese de Caicó, 1943, p. 7, grifo nosso). A Casa do Pobre vinha para patrocinar as bases legais da cooperação entre a União, o Estado e a Igreja Católica local no cumprimento do amparo aos menores pobres, de 7 a 12 anos de idade, mediante a oferta da educação escolar associada com a assistência material, moral, religiosa e a preparação para a vida. (BARRETO, 1952).

A sociedade moderna vista como a sociedade da escolarização em direção à educação mais ou menos homogênea da criança e da juventude "[...] se consubstancia no princípio de 'ensinar a muitos como se fosse um só"”. (BARROSO, 2004, p. 106, grifo do autor). Os ensinamentos de saberes culturais cujo alicerce é, antes de tudo, um ler, um escrever e um contar, ao lado da imposição de hábitos, atitudes e de condutas disciplinares condizem, indiscutivelmente, com mutações existenciais do indivíduo. (ARAÚJO; BRITO; MEDEIROS NETA, 2007).

Para além de tais requisitos liberais, e em face dos avanços da pedagogia escolanovista, a escola moderna não prescinde do uso diversificado de utensílios pedagógicos ou materiais escolares, efetivamente como auxiliadores da dinâmica do ato de ensinar coletivamente e das aprendizagens individuais.

Considerando estritamente as singularidades dessa instituição socioeducacional católica - particularmente a Escola Rural do Pobre "Jardim Seridoense" - ancoramo-nos, para sua análise histórica, nos construtos teóricos de cultura escolar e de cultura de escola, tal como abordados pelo historiador da educação João Barroso (2004), a partir das inter-relações entre organização societária e instituição educacional, que alicerçam metodologicamente a análise documental e histórica.

O historiador João Barroso (2004) ensaia uma distinção entre cultura escolar e cultura de escola. O primeiro construto teórico, cultura escolar, é visto a partir das inter-relações entre organização societária e instituição escolar. Esta é parte da cultura geral que a fundamenta e a estrutura. O construto teórico, cultura de escola, é também entendido pela ótica das inter-relações entre organização societária e instituição escolar, mas de forma menos intensa e mais maleável, até por forças de 
circunstâncias variadas.

Mediante tais indicativos históricos e metodológicos propusemos a presente investigação nucleada em torno da problemática do alfabetismo, para interrogar o objeto de estudo a escolarização da criança pobre e seus utensílios pedagógicos no intramuro da Escola [do Pobre Rural] "Jardim Seridoense", no período de 1943 e 1951, com o objetivo de refletir sobre a materialidade educativa ali instaurada.

Pensar a materialidade educativa ali instaurada, exigiu como pressuposto o cotejamento dos dados contidos nas fontes documentais analisadas (atas, legislação, relatórios, artigos de jornais, relatos orais), para averiguar os acervos de utensílios pedagógicos protocolados, os quais são prescritivos de uma dada cultura escolar e uma cultura de escola. Explica-nos Abreu Júnior:

De fato, os materiais e seu uso na escolarização são a prioridade, mas eles têm que estar compreendidos em seu contexto, tanto espacial quanto histórico. Não há materiais soltos, sem gênese e, conseqüentemente, sem valor social e político. (ABREU JÚNIOR, 2005, p. 161).

Ao enveredar pela documentação concernente à Escola do Pobre Rural "Jardim Seridoense", pudemos assim constatar os dois momentos que se sucederam no período investigado (1943-1951). O primeiro momento, de 1943 a 1945, foi quando o padre Eymard L'E. Monteiro esteve como seu diretor, deixando basicamente como únicos registros as atas das sessões ordinárias da Casa do Pobre relativas às assinaturas dos termos de compromissos entre a Legião Brasileira de Assistência (LBA) e a Diocese de Caicó (representadas, respectivamente, pela senhora Ana da Cunha de Medeiros e pelo bispo Dom José de Medeiros Delgado), firmados com a intenção de promover o amparo da criança pobre, especialmente no tocante à alimentação e aos materiais educacionais diversos. (Ata da $3^{\mathrm{a}}$ sessão ordinária da Casa do Pobre, 1943). O segundo momento, de 1945 a 1958 (extrapolando a delimitação cronológica da investigação), veio a ser o período de tempo em que o padre Aluízio Rocha Barreto dirigiu a Instituição. Sob sua regência, desenvolveu-se um ambicioso trabalho educacional para projetá-la. Essa é 
também uma época em que se contabilizam ricos registros.

A escolarização associada com a assistência social destinada à criança pobre era apresentada no Decreto-Lei $\mathrm{n}^{\circ} 2.024$, de fevereiro de 1940 (que criou o Departamento Nacional da Criança), como uma das modalidades que interferiam no desenvolvimento mental, moral, físico e na preparação para a vida. É com esse espírito que o bispo Dom Delgado leva adiante o projeto estatutário da Escola Rural "Jardim Seridoense", deliberadamente destinado a "Velar pela saúde, bem-estar e necessidades da infância pobre [...]." (Estatutos da Escola Rural "Jardim Seridoense", 1948; Relatório de 1948. apresentado ao Exmo. e Revmo. Dom José de Medeiros Delgado..., 1949, fl. 8). Em sua dimensão concreta, os propósitos do governo de Getúlio Vargas e do governo da Diocese de Caicó dependiam, indubitavelmente, de variáveis pedagógicas de ordem material.

Conforme registram os termos da cooperação celebrada entre a Igreja Católica e os governos federal, estadual e municipal, a Escola do Pobre (como então chamada) foi inaugurada no dia 10 de maio de maio de 1943, na cidade de Jardim do Seridó (RN), Paróquia de Nossa Senhora da Conceição, juntamente com a Casa do Pobre, posteriormente Casa de Menores.

A cerimônia da inauguração ocorreu perante uma assembléia de autoridades e de fiéis composta pelo padre Eymard L'E. Monteiro (Vigário da Paróquia e Diretor da Escola do Pobre), Pedro Isidro de Medeiros (Prefeito de Jardim de Seridó), Miguel da Costa Cirne (Presidente da Casa do Pobre), Anita Costa e Manoel da Costa Cirne (Secretária e Tesoureiro da Casa do Pobre e da Escola do Pobre), dentre outras pessoas.

À semelhança de suas congêneres católicas criadas pelo bispo de Caicó, a Escola do Pobre ergue-se como uma instituição social, com o ensejo da responsabilidade pública de que as crianças de 7 a 12 anos se apropriassem de conhecimentos culturais mínimos, se instruíssem de atitudes morais e religiosas, de hábitos de trabalho para os ofícios de artesão, de agricultor, de sapateiro, de costureira e de cozinheira em demandas à época e se dotassem de costumes de higiene salutares. (ESTATUTOS DA ESCOLA RURAL "JARDIM SERIDOENSE", 1948). Com esse compromisso educativo, a escolarização da criança pobre de Jardim do Seridó foi absolutamente bem-recebida localmente.

Inicialmente, a Escola do Pobre funcionou precariamente em salas

Educ. e Filos. Uberlândia, v. 23, n. 46, p. 19-36, jul./dez. 2009 
de residências familiares; posteriormente, na casa da Irmandade do Rosário, e em prédio alugado ou cedido. Conforme o padre Aluízio Rocha Barreto (diretor de 1945 a 1958), eram ambientes que não satisfaziam as exigências pedagógicas, particularmente pelo fato de as crianças geralmente assistirem às aulas sentadas no chão. (BARRETO, 2007).

Em meio às difíceis atividades iniciais, o bispo Dom José de Medeiros Delgado já abençoou, a 13 de agosto de 1945, a pedra fundamental do local da construção do edifício da Escola, bem ao lado do Santuário do Sagrado Coração de Jesus. (Paróquia de Nossa Senhora da Conceição, 1945). Nesse ínterim, dada a sua uniformidade pedagógica com o ensino regular, passou a denominar-se Escola Rural "Jardim Seridoense". (BARRETO, 2007).

Em vista de um ambiente compatível com os cuidados higiênicos e aprazíveis, para a labuta de uma educação escolar, "[...] enquadrada nos moldes da pedagogia moderna [...]" (PARÓQUIA DE NOSSA SENHORA DA CONCEIÇÃO, 1952, fl. 1), as escavações do alicerce do prédio escolar iniciaram-se, a 11 de setembro de 1943, mediante as subvenções da Diocese de Caicó, do Ministério da Justiça e Negócios Interiores e também da população local. Em virtude dessa cooperação solidária e dos esforços do padre Aluízio Rocha Barreto, o edifício da Escola Rural "Jardim Seridoense" foi construído mais ou menos em seis anos (19451951), dotado de classes de aulas, salas-oficinas, biblioteca, diretoria, salão de festas, sala de visitas, pátio interno, refeitório, ambulatório, cozinha, despensa, banheiros e cisternas para reter a água da chuva.

$\mathrm{O}$ confronto entre a pedagogia moderna ou escolanovista, que referenciava a escolarização da criança pobre de Jardim do Seridó, e os utensílios pedagógicos correlatos àquela pedagogia e também a uma dada cultura escolar e cultura de escola, já se observa esforços de uniformidade no tocante à seriação, obrigatoriedade da freqüência, fardamento, normas disciplinares, constância do tempo das aulas, férias, regularidade das festividades e da utilização de técnicas didáticas pelos professores, segundo o estilo escolar adotado nas demais escolas públicas. Porém, os esforços de homogeneização dispensaram por certo período às classes únicas de meninas e meninos. (GÓIS, 2008).

A escola e a escolarização, dela procedente, destinavam-se a ensinar ao 
menino e à menina pobre de Jardim do Seridó, um conjunto de conhecimentos úteis ligados à vida urbana, mas também no que tange ao meio rural, de onde muitos vinham com os pais, devido às sucessivas secas. Por todas essas razões, trabalhava o diretor da Escola Rural "Jardim Seridoense" para sensibilizar os segmentos populares e também os segmentos não populares à alternativa da escolarização à ociosidade dessa meninada. Como não poderia deixar de acontecer, as cerimônias religiosas era o momento planejado pelo padre Aluízio Rocha para tais pregações. Por suas palavras, nos dias das festividades de São José (8, 9 e 10 de outubro), houve manifestações de "[...] alegria, fé e vontade do povo em auxiliar materialmente os serviços [do edifício escolar] iniciados em setembro." (Paróquia de Nossa Senhora da Conceição, 1945, fl. 5).

É de se recordar que o projeto da escolarização, concomitante à assistência destinada à criança pobre do Brasil, circunscrevia-se a uma agenda nacional condizente com um desenvolvimento mental, moral, físico e a preparação para a vida - com pretensões liberalizantes de homogeneidade, de equalização e de regulação social. Qual teria sido o trabalho pedagógico de padre Aluízio Rocha, para materializar tais preceitos nas práticas educativas específicas da vida escolar?

No cumprimento do seu magistério sacerdotal, o padre Aluízio Rocha compôs o quadro docente de modo a harmonizar-se com os estudantes matriculados por classe de aula. No ano de 1945, terceiro ano de funcionamento da Escola Rural "Jardim Seridoense", havia 100 crianças matriculadas (50 meninas e 50 meninos) e as professoras Cândida Dantas, Maria José Campos e Nice de Oliveira Dantas, para o ensino da primeira e segunda série primária. Em 1948, estavam 78 alunos matriculados (35 meninas e 43 meninos) e as professoras Maria José Campos, Nice de Oliveira Dantas e Olindina Dantas, para o ensino da primeira, segunda e terceira série primária. No ano de 1949, existiam 62 alunos matriculados (32 meninas e 30 meninos) e as professoras Nice de Oliveira Dantas, Maria José Campos, Maria de Lourdes de Azevedo e Calpurnia Caldas de Amorim, para o ensino da primeira, segunda, terceira e quarta série primária. Em 1950, foram 76 alunos matriculados (35 meninas e 41 meninos) e as professoras Nice de Oliveira Dantas, Maria José Campos, Olindina de Oliveira Dantas e Rita Aderaldo, para o ensino da primeira, 
segunda, terceira e quarta série primária. No ano de 1951, havia 53 alunos matriculados (20 meninas e 33 meninos) e as professoras Nice de Oliveira Dantas, Maria José Campos, Maria de Lourdes de Azevedo, Olindina de Oliveira Dantas e Clenita Dantas, para o ensino da primeira, segunda, terceira e quarta série primária.

Por um lado, a ampliação das classes de aula fez-se, principalmente, por força do desvelo, da generosidade e da disciplina das professoras (geralmente possuíam a quarta-série primária) com a escolarização dos seus alunos e o sucesso deles. Por outro lado, pela constância da regularidade das subvenções das instituições cooperadoras e dos donativos individuais. Aí, estaria, certamente, o encorajamento do padre Aluízio Rocha em expandir a Escola Rural "Jardim Seridoense" pelos "povoados capelas" de Ouro Branco e de São José do Seridó, pertencentes à Paróquia de Nossa Senhora da Conceição de Jardim do Seridó.

Pelos vazios da extensão da escolarização, as crianças pobres nesses "povoados capelas", escolas paroquiais foram instaladas como sendo filiais da Escola Rural "Jardim Seridoense", inauguradas, respectivamente, em 6 e 20 de fevereiro de 1950, com a permissão da autoridade diocesana. Na Escola Paroquial Divino Espírito Santo, de Ouro Branco, já se matricularam, imediatamente, 47 crianças para a classe da primeira série da prof. ${ }^{\text {a }}$ Pequena Medeiros. Enquanto na Escola Paroquial São José, de São José do Seridó, a matrícula foi de 37 crianças, para a classe de primeira série da prof. ${ }^{\text {a }}$ Maria Aparecida de Azevedo. (Termo de encerramento da Escola Rural "Jardim Seridoense", 1949; BARRETO, 2007).

Do ponto da política socioeducacional liberalizante do governo Getúlio Vargas, a escolarização pública, eminentemente a escolarização da criança pobre, constituía matéria de intervenções estritas de órgãos federais, estaduais, municipais e católicos. Se observarmos o "Livro de relatórios" (1947-1950) e o "Livro de atas" (1945-1951), percebemos os crescentes aportes das subvenções governamentais, principalmente os da L.B.A., como aqui visto: Legião Brasileira de Assistência - L.B.A. (Cr\$ $3.300,00+6.302,00+31.800,00+33.200,00=\mathrm{Cr} \$ 74.602,00)$, Serviço Estadual de Reeducação e Assistência Social - SERAS (Cr\$12.000,00 + $15.000,00=\mathrm{Cr} \$ 27.000,00)$, municipalidade $(\mathrm{Cr} \$ 3.000,00+3.000,00+$ $3.000,00+3.000,00+10.000,00=\mathrm{Cr} \$ 22.000,00)$ e população local $(\mathrm{Cr} \$$ 
$3.000,00+10.000,00=\mathrm{Cr} \$ 13.000,00)$.

Era basicamente para a criança pobre que se deveriam dirigir os seus planos, com metas, e com resultados esperados do ponto de vista qualitativo e quantitativo. Isso talvez explique, parcialmente, a criação das delegacias federais da criança nas capitais brasileiras, órgão do Departamento Nacional da Criança. E, igualmente, explique a posse de Dom Delgado, em setembro de 1943, na função de Delegado Regional do Seridó, espécie de escritório da L.B.A. em Caicó, sob sua gerência. (1500 menores amparados no Seridó pela L.B.A...., 1943).

Ao considerar que aqueles órgãos estatais e católicos asseguravam às subvenções concernentes às demandas prementes da criança-aluno pobre de Jardim do Seridó, havemos de indagar acerca dos utensílios pedagógicos correlatos com uma dada cultura escolar e cultura de escola, que pretendiam impulsionar um desenvolvimento mental, moral, físico e a preparação para a vida (Decreto-Lei $n^{\circ} 2.024$ de 17 fevereiro, de 1940 que ordenou o Departamento Nacional da Criança) e que ainda encorajava a Igreja local a velar pela saúde, o bem-estar e as necessidades humanas da infância pobre. (Estatutos da Escola Rural "Jardim Seridoense", 1948)?

A oferta da educação escolar complementada com a assistência moral, religiosa física e com o preparo para a vida era assim "[...] o principal meio de atrair os alunos pobres [de Jardim do Seridó] à escola desde que vem de encontro à fome e à miséria em que habitavam [...]." (Relatório de 1947. Apresentado ao Excelentíssimo e Reverendíssimo senhor Dom José de Medeiros Delgado..., 1948, fl. 5). Também assinala de antemão os acervos (por assim dizer) de utensílios pedagógicos integrantes da materialidade educativa da Escola Rural "Jardim Seridoense". Agrupando-os pelos valores de pagamento efetuados no período de 1947 a 1951 percebemos aqueles utensílios pedagógicos preponderantes para a materialidade educativa da Escola Rural "Jardim Seridoense" que seriam - alimentação, vestuário e fardamento, objetos escolares, professores e mobiliário, conforme quadro 1. 


\begin{tabular}{|c|c|c|}
\hline Período & Utensílios pedagógicos & Valor (Cr\$) \\
\hline 1947 & $\begin{array}{l}\text { Alimentação (11.099) } \\
\text { Vestuário e fardamento (300) } \\
\text { Objetos escolares (2005) } \\
\text { Professoras (3) } \\
\text { Mobiliário }\end{array}$ & $\begin{array}{l}\text { Cr\$12.260,00 } \\
\mathrm{Cr} \$ 2.952,00 \\
\mathrm{Cr} \$ 2.648,00 \\
\mathrm{Cr} \$ 3.000,00 \\
\mathrm{Cr} \$ 670,00\end{array}$ \\
\hline 1948 & $\begin{array}{l}\text { Alimentação (8.238) } \\
\text { Vestuário e fardamento (235) } \\
\text { Objetos escolares (1.811) } \\
\text { Professoras (3) } \\
\text { Mobiliário }\end{array}$ & $\begin{array}{l}\text { Cr\$ } 12.357,00 \\
\mathrm{Cr} \$ 2.505,00 \\
\mathrm{Cr} \$ 2.349,00 \\
\mathrm{Cr} \$ 3.000,00 \\
\mathrm{Cr} \$ 670,00 \\
\end{array}$ \\
\hline 1949 & $\begin{array}{l}\text { Alimentação (8.531) } \\
\text { Vestuário e fardamento (107) } \\
\text { Objetos escolares (829) } \\
\text { Professoras (4) } \\
\text { Mobiliário } \\
\end{array}$ & $\begin{array}{l}\text { Cr\$ } 18.602,00 \\
\text { Cr\$ } 913,00,00 \\
\text { Cr\$ } 333,70 \\
\text { Cr\$ } 4.345,00 \\
\text { Cr\$ } 5.635,30 \\
\end{array}$ \\
\hline 1950 & $\begin{array}{l}\text { Alimentação (9.432) } \\
\text { Vestuário e fardamento (104) } \\
\text { Objetos escolares (796) } \\
\text { Professores (6) } \\
\text { Mobiliário }\end{array}$ & $\begin{array}{l}- \\
- \\
- \\
- \\
-\end{array}$ \\
\hline 1951 & $\begin{array}{l}\text { Alimentação (9.955) } \\
\text { Vestuário e fardamento (977) } \\
\text { Objetos escolares (104) } \\
\text { Professoras ( } 6) \\
\text { Mobiliário }\end{array}$ & $\begin{array}{l}- \\
- \\
- \\
- \\
-\end{array}$ \\
\hline
\end{tabular}

Fonte: Livro de relatórios e Livro de atas (1945-1951)

Em sendo as crianças-alunas da Escola Rural "Jardim Seridoense", em sua maioria, destituída de quaisquer recursos (Relatório de 1947. Apresentado ao Excelentíssimo e Reverendíssimo senhor Dom José de Medeiros Delgado..., 1948), o planejamento das instituições cooperadoras já orientava no sentido de que cada estudante "ganhasse" duas refeições diárias (almoço sólido e merenda escolar), que, a um só tempo, robustecia o organismo, melhorava o desempenho educacional e estimulava a continuidade da escolarização primária. 
À luz dos exercícios da leitura, da escrita e do falar corretamente, os objetos escolares distribuídos homogeneamente entre os estudantes, como parece evidente, seriam: livro, caderno, lápis, borracha, caneta e tinteiro. Em vista da disciplina escolar, da uniformidade de símbolos e da regulação social, o projeto educativo da Escola Rural "Jardim Seridoense" não dispensava o uso da palmatória e de uma bandeira do Brasil hasteada em cada classe de aula. Urgia, contudo, ordenar as classes coletivas com um mobiliário mínimo, a princípio, tamborete e banco comprido; posteriormente, carteira individual, quadro-negro com cavalete, birô e a cadeira da professora.

A Escola, no contraponto da vida d'antes daquela meninada, esmerava-se para que a escolarização repercutisse, no ambiente familiar e social, pelas lições dos livros, pelas aulas de catecismo, pelas festas escolares e pelos desfiles cívicos. No ano de 1949, a Escola Rural "Jardim Seridoense" recebeu do Instituto Nacional do Livro a doação de aproximadamente 300 livros para a biblioteca, no intuito de que a leitura tornasse assim uma rotina, quase um hábito de cada aluno, como imperativo do aprimoramento mental e material da sociedade.

Para que o estudante efetivamente se apossasse dos preceitos básicos da religião católica, tinham por obrigação freqüentar a aula de catecismo (que preparava para a primeira comunhão), assistir à missa da páscoa, dos domingo e dias santos (inclusive no período das férias escolares), bem como às novenas do mês de maio, e dentre outras obrigações, confessarem-se, por exemplo.

Nota-se que havia, por parte da direção da Escola Rural "Jardim Seridoense", um movimento cultural de divulgação dos ensinamentos veiculados pelos professores nas matérias de Leitura e Linguagem Oral e Escrita; Iniciação Matemática; Geografia e História do Brasil; Conhecimentos gerais aplicados à vida social, à educação para a saúde e ao trabalho; Desenho e Trabalhos Manuais; Canto Orfeônico e Educação Física (Estabelecidas pela Lei Orgânica do Ensino Primário, aprovada pelo Decreto-Lei de $\mathrm{n}^{0} 8.529$, de 2 de janeiro de 1946). Daí, nas festividades de encerramento do ano letivo e de comemoração do aniversário da Escola Rural "Jardim Seridoense", sempre no início do mês de dezembro, os estudantes reapresentavam artisticamente, digamos assim, os aprendizados adquiridos nas lições de estudo, pela forma de canto, canto orfeônico, comédia, diálogo, poesia, trovas populares, conforme ilustrado no quadro 2 .

Educ. e Filos. Uberlândia, v. 23, n. 46, p. 19-36, jul./dez. 2009 
QUADRO 2

\begin{tabular}{|c|c|c|c|c|}
\hline $\begin{array}{c}\text { Leitura e } \\
\text { Linguagem } \\
\text { Oral e Escrita }\end{array}$ & $\begin{array}{c}\text { Geografia e } \\
\text { História do } \\
\text { Brasil }\end{array}$ & \begin{tabular}{|c|} 
Conhecimentos \\
gerais aplicados \\
à vida social, à \\
educação para \\
a saúde e ao \\
trabalho \\
\end{tabular} & $\begin{array}{c}\text { Canto } \\
\text { Orfeônico }\end{array}$ & $\begin{array}{l}\text { Educação } \\
\text { Física }\end{array}$ \\
\hline $\begin{array}{l}\text { Poesia | Língua } \\
\text { materna }\end{array}$ & $\begin{array}{c}\text { Canto } \mid \\
\text { Descoberta da } \\
\text { América }\end{array}$ & $\begin{array}{c}\text { Comédia } \mid \mathrm{A} \\
\text { roceira honrada }\end{array}$ & $\begin{array}{l}\text { A pátria } \\
\text { gloriosa }\end{array}$ & $\begin{array}{l}\text { Ginástica } \\
\text { rítmica }\end{array}$ \\
\hline $\begin{array}{c}\text { Poesia } \mid \mathrm{O} \\
\text { alfabeto }\end{array}$ & $\begin{array}{c}\text { Hino } \mid \\
\text { Independência d } \\
\text { o Brasil } \\
\end{array}$ & $\begin{array}{c}\text { Diálogo | As } \\
\text { profissões }\end{array}$ & Brasil & Jogo de futebol \\
\hline $\begin{array}{c}\text { Poesia } \mid \mathrm{A} \\
\text { escola }\end{array}$ & $\begin{array}{c}\text { Poesia } \mid 7 \mathrm{de} \\
\text { setembro }\end{array}$ & $\begin{array}{c}\text { Diálogo | O } \\
\text { corpo humano }\end{array}$ & $\begin{array}{l}\text { Cores da } \\
\text { Bandeira }\end{array}$ & \\
\hline $\begin{array}{c}\text { Poesia } \mid \mathrm{O} \\
\text { estudo }\end{array}$ & Poesia $\mid$ A pátria & $\begin{array}{c}\text { Canto | Vida } \\
\text { malvada }\end{array}$ & Amanhã & \\
\hline $\begin{array}{l}\text { Trovas } \\
\text { populares }\end{array}$ & $\begin{array}{c}\text { Diálogo } \mid \\
\text { Libertação dos } \\
\text { escravos } \\
\end{array}$ & $\begin{array}{l}\text { Canto | Ser } \\
\text { humilde }\end{array}$ & $\begin{array}{l}\text { São João } \\
\text { Dararão }\end{array}$ & \\
\hline $\begin{array}{c}\text { Poesia } \mid \\
\text { Pindorama } \\
\end{array}$ & $\begin{array}{c}\text { Poesia } \mid \mathrm{O} \\
\text { cruzeiro do sul } \\
\end{array}$ & Poesia $\mid$ A visita & Luar do sertão & \\
\hline $\begin{array}{c}\text { Canto } \mid \\
\text { Aquarela do } \\
\text { Brasil } \\
\end{array}$ & $\begin{array}{c}\text { Poesia } \mid \text { Pontos } \\
\text { cardeais }\end{array}$ & $\begin{array}{c}\text { Poesia } \mid \text { Duas } \\
\text { virtudes }\end{array}$ & O galo & \\
\hline \multirow[t]{4}{*}{$\begin{array}{c}\text { Valsa } \mid \text { Flor de } \\
\text { lótus } \\
\end{array}$} & $\begin{array}{c}\text { Poesia } \mid \text { Minha } \\
\text { terra }\end{array}$ & Poesia| Mãe & & \\
\hline & $\begin{array}{c}\text { Poesia } \mid \mathrm{A} \\
\text { árvore }\end{array}$ & $\begin{array}{c}\text { Poesia } \mid \text { A } \\
\text { velhice }\end{array}$ & & \\
\hline & $\begin{array}{c}\text { Poesia } \mid \\
\text { Anoitecer }\end{array}$ & Poesia |Deus & & \\
\hline & & $\begin{array}{c}\text { Poesia } \mid \text { Ave- } \\
\text { maria }\end{array}$ & & \\
\hline
\end{tabular}

Fonte: Livro de atas (1948-1951)

No seu conjunto, esse movimento cultural, empreendido pelo padre Aluízio Rocha, ensejava que as pessoas gradas (assim chamado o prefeito, vice-prefeito, coordenadora da LBA, comerciantes, representantes de irmandades e de associações) se inteirassem dos aprendizados culturais requeridos por uma urbanidade ainda carente de esperanças prósperas para a 
infância pobre. Ora, a Escola do Pobre - como enfaticamente referenciavam algumas daquelas pessoas gradas - igualava-se a um bem social não somente para a criança-aluno pobre mas também para a sociedade, que recebia dos bancos escolares os homens e as mulheres de bem do futuro.

A esse respeito, vale dizer, que aquelas crianças, aluno e aluna da Escola do Pobre, ascenderam para além da ordem social d'antes. Por exemplo, Lourival Vasconcelos (hoje é comerciante e mora em Minas Gerais), Ildete Gomes (exerceu o cargo de diretora da Escola Rural "Jardim Seridoense", após sua estadualização, por volta dos anos de 1980, e cursou Pedagogia no Campus da UFRN em Caicó), Moacir Gomes (comerciante aposentado) e Miguel Toscano Filho (pertence ao quadro intermediário da Polícia Militar do Estado de São Paulo). (MORAIS, 2008).

Pode-se dizer que havia por parte das professoras um devotamento fraterno e também uma zelosa disciplina para com a escolarização da criança pobre jardinense, fazendo com que a Escola Rural "Jardim Seridoense" viesse a ser o "seu grande mundo" das aprendizagens mínimas (VIEIRA, 1957) e ainda da iniciação em "[...] pequenas artes e ofícios [...]" (Estatutos da Escola Rural "Jardim Seridoense", 1948, fl. 1) que fruiriam no estímulo ao trabalho.

Em dezembro de 1953 - na festividade de encerramento do ano letivo e comemoração do aniversário da Escola Rural "Jardim Seridoense" -, o corpo docente, discente e as pessoas gradas da cidade presenciaram a fundação do Clube de Corte e Costura Nossa Senhora de Fátima, destinado às estudantes maiores da Escola, com extensão a senhoras e senhorinhas da cidade. (Termo de encerramento da Escola RURAL "Jardim Seridoense", 1953). Na mais fiel reciprocidade entre escolarização e preparação para a vida, os meninos foram agraciados com o Clube Agrícola, que, registrado no Ministério da Agricultura, colaborava com ferramentas do trabalho e sementes para o plantio de hortaliças, verduras e de frutas destinadas às duas refeições diárias, com base em feijão, arroz, carne de jabá, sopa, leite, bolacha. (BARRETO, 2007.1).

A vida citadina, com meninos e meninas nas salas de aula e nas oficinas de iniciação para o hábito de trabalho, era a dimensão social para a qual se voltaria a materialidade educativa da Escola [do pobre] Rural "Jardim Seridoense". A escolarização e seus utensílios pedagógicos firmariam, portanto, para as crianças, os pais e as pessoas gradas da cidade, referências do rígido ritual da educação escolar para o progresso individual e a esperança 
de mobilidade social. Alimentação, vestuário e fardamento, mobiliário, professores, edifício, objetos escolares, bandeira do Brasil, palmatória, ferramentas, oficinas de trabalho, compunham um acervo de utensílios pedagógicos que patenteavam a materialidade educativa dessa Escola da criança pobre, sob a proteção material e espiritual da Diocese de Caicó, do MEC, do Ministério da Agricultura, da L.B.A., do Seras, da municipalidade, da população local. Outrossim, ensaiavam-se, nas práticas específicas da vida escolar, preceitos da pedagogia escolanovista, bem como consubstanciava-se uma cultura escolar uniformizada, igualmente, uma cultura de escola católica.

\section{Referências}

ABREU JÚNIOR, Laerthe de Moraes. Apontamentos para uma metodologia em cultura material escolar. Pro-Posições, Campinas, v. 16, n. 46, p. 145-164, jan./abr. 2005.

ARAÚJO, Marta Maria de; BRITO, Paula Sonia de; MEDEIROS NETA, Olívia Morais de; Quão alfabetizadoras formas as Escolas dos Pobre da Diocese de Caicó-RN (1943-1951)? In: Encontro Nacional Perspectvas do Ensino de História, 7., 2007, Natal. Anais... Natal: Universidade Federal do Rio Grande do Norte/Associação de História, 2007. 1 CD-ROM.

BARROSO, João. Cultura, cultura escolar e cultura de escola. In: FERREIRA, António Gomes. (Org.). Escolas, culturas e identidades. Coimbra: Ediliber, 2004. (v. 1).

BARRETO, Padre Aluízio Rocha. Histórico da Escola Rural "Jardim Seridoense". Livro da Escola Rural "Jardim Seridoense" (1952-1960). Jardim do Seridó, 10 maio. 1952. (Manuscrito).

. Relato escrito sobre a Escola Rural "Jardim Seridoense". Fortaleza, 8 maio. 2007.

. Relato oral sobre a Escola Rural "Jardim Seridoense". Jardim do Seridó, 4 dez. 2007.1.

BRASIL. Decreto-Lei $n$. 2.024, de 17 de Fevereiro de 1940. Fixa as bases da organização da proteção à maternidade, à infância e à adolescência em todo o país. Disponível em: www.ciespi.org.br/base_legis/baselegis_list

Educ. e Filos. Uberlândia, v. 23, n. 46, p. 19-36, jul./dez. 2009. 
by_period.php Acesso em: 13 maio. 2008.

. Decreto-lei n. 8.529, de 2 de janeiro de 1946. Lei Orgânica do Ensino

Primário. Disponível em: http://www.soleis.adv.br Acesso em: 23 maio. 2008.

INSTITUTO BRASILEIRO DE GEOGRAFIAEESTATÍSTICA.

Censo Demográfico do Rio Grande do Norte: 1940. Rio de Janeiro: Serviço Gráfico do IBGE, 1952.

DELGADO, Dom José de Medeiros. DECRETO de Fundação da Casa do Pobre. Caicó: Livro de Tombo 1 da Diocese de Caicó, 1943. (Manuscrito). . Ação social. Natal: Serviço de Publicidade da LBA no Rio Grande do Norte, [1944].

ESCOLA RURAL "JARDIM SERIDOENSE”. RELATÓRIO DE 1947. Apresentado ao Excelentíssimo e Reverendíssimo Senhor Dom José de Medeiros Delgado, bispo de Caicó, pelo padre Aluízio Rocha Barreto, Diretor da Escola Rural "Jardim Seridoense", em 30 de janeiro de 1948. Livro de relatórios 1947-1949. Jardim do Seridó, 30 jan. 1948. (Manuscrito). . RELATÓRIO DE 1948. Apresentado ao Exmo e Revmo Dom José de Medeiros Delgado. D. D. bispo da Diocese de Caicó, pelo padre Aloísio Rocha Barreto, Diretor da Escola Rural "Jardim Seridoense", em 30 de janeiro de 1949. Livro de relatórios 1947-1949. Jardim do Seridó, 30 jan. 1948. (Manuscrito).

. TERMO de Encerramento da Escola Rural "Jardim Seridoense." Livro de atas. Jardim do Seridó, 7 dez. 1949. (Manuscrito).

- TERMO(S) de encerramento(s) da Escola Rural "Jardim Seridoense." Livro de atas. Jardim do Seridó, 1948-1951. (Manuscrito).

TERMO de Encerramento da Escola Rural "Jardim Seridoense." Livro de atas. Jardim do Seridó, 1953. (Manuscrito).

GÓIS, Francisca Silva. Relato oral sobre a Escola Rural "Jardim Seridoense". Jardim do Seridó, 8 mar. 2008.

MORAIS, Sebastião Arnóbio de. Relato oral sobre a Escola Rural "Jardim Seridoense”. Jardim do Seridó, 29 maio. 2008.

PARÓQUIA de Nossa Senhora da Conceição. Ata da instalação da Casa do Pobre nesta cidade de Jardim do Seridó. Livro de atas. Jardim do Seridó, 
10 maio 1943. (Manuscrito).

. ATA DA $3^{\text {a }}$ SESSÃO Ordinária da Casa do Pobre. Livro de atas. Jardim do Seridó, 3 out. 1943. (Manuscrito).

ESTATUTOS da Escola Rural "Jardim Seridoense”. Diário Oficial [do] Rio Grande do Norte, Natal, RN, 3 abr. 1948. p. 3 e 4.

PARÓQUIA de Nossa Senhora da Conceição. Livro de tombo. Jardim do Seridó, 8-10 out. 1945. (Manuscrito).

Livro de Tombo. Jardim do Seridó, 10 maio 1952. (Manuscrito).

RIO GRANDE DO NORTE. ESTATUTOS da Casa do Pobre da Diocese de Caicó. Diário Oficial [do] Rio Grande do Norte, Natal, RN, 25 abr. 1943. p. 7.

SOUSA, Cynthia Pereira de. Saúde, educação e trabalho de crianças e jovens: política social de Getúlio Vargas. In: GOMES, Angela de Castro. (Org.). Capanema: o ministro e seu ministério. Rio de Janeiro: Editora FGV, 2000.

VIEIRA, Irmã Maria Augusta. Termo de visita. Livro da Escola Rural "Jardim Seridoense" (1952-1960). Jardim do Seridó, 28 nov. 1957. (Manuscrito).

1500 MENORES Amparados no Seridó pela L.B.A., Casa do Pobre e Serviço de Reeducação e Assistência Social. A República, Natal, p. 7, 17 set. 1943.

Data de registro: 15/02/09

Data de aceite: 18/03/09 